\title{
Availability of Copper in Freeze-dried Herbage and Herbage Extracts to Copper-deficient Rats
}

\author{
By C. F. MILLS \\ Rowett Research Institute, Bucksburn, Aberdeenshire
}

(Received 13 June 1955)

The object of this work was to evolve a satisfactory technique for the production of copper-deficient rats for copper-metabolism studies and to use these animals to investigate the dietary availability of ionic copper and the copper of herbage.

It has been shown (Mills, 1954, 1955) that most of the copper in herbage exists as organic complexes. Few studies on the dietary availability of such organic complexes of copper have been reported. Tschirch (1893) claimed that the copper of copper phyllocyanate (a complex isolated from green vegetables to which copper had been added and to which he ascribed the formula $\left.\left(\mathrm{C}_{24} \mathrm{H}_{27} \mathrm{~N}_{2} \mathrm{O}_{4}\right)_{2} \mathrm{Cu}\right)$ was absorbed from the digestive tract of dogs and rabbits despite the fact that it resisted peptic and pancreatic digestion in vitro, but Taylor, Long \& Chittenden (1913) could not confirm this finding. Schultze, Elvehjem \& Hart (1934, 1936) investigated the availability of copper in various compounds as a supplement to fresh liquid milk and iron for haemoglobin formation. The copper of 'copper caseinate', glycine-amide biuret, alanine-amide biuret, copper aspartate, copper citrate and haemocyanin was readily utilized, but the results of in vitro experiments led the authors to suggest that these copper complexes decomposed to liberate ionic copper in the acid portions of the digestive tract. On the other hand, the copper of copper haematoporphyrin, which resisted peptic digestion in vitro, was not utilized by the rat.

After extending their investigations to study the availability of copper in whole wheat and other natural food materials Schultze et al. (1934) comment 'it must be borne in mind that the addition of natural food materials to the [liquid] milk-iron [basal] diet may improve the severe condition of the [copper- and iron-deficient] anemic rats through factors other than their content of available copper'. This situation would obviously complicate the interpretation of trials designed to measure the availability of a specific trace nutrient. Examination of the nutrient content of the fresh-milk basal diet used by Schultze $e t$ al. and many other workers to produce copper deficiency suggests that this diet, even when supplemented with iron, is inadequate to meet the requirements of the growing rat, as it is deficient in methionine, valine, $\alpha$-tocopherol, pantothenic acid and energy (Mills, 1955). In the preparation of a basal diet for the work to be described these deficiencies were remedied by appropriate supplementation of fresh whole milk.

It is common practice in studies of copper metabolism to quote blood- and livercopper analyses as indices of the utilization of dietary copper. This procedure is open to criticism, particularly when natural food materials are under test, because of the 
possible interference of dietary factors modifying the physiological utilization of copper. Thus in the sheep (Marston, I950) and the rat (Marston, 195 I, 1952) it has been shown that the feeding of molybdenum may precipitate obvious signs of copper deficiency even when the copper content of the blood and liver is not low. Furthermore, Allcroft \& Parker (I949) have found a steady decline in blood-copper values to be associated with a marked improvement in the clinical condition of calves transferred to healthy pastures from a 'hypocupraemic scours' area. It was considered advisable in the present investigation to assess the availability of dietary copper by the physiological response of copper-deficient rats to the feeding of the test supplements augmented by measurement of liver-copper stores at the end of the experimental period.

The rate of haemoglobin regeneration in the anaemic rat supplied with adequate dietary iron has been used by Schultze (1940), Schultze et al. (1934, 1936) and Elvehjem (r935) to indicate the availability of copper in the diet. A further physiological index of utilization of dietary copper is provided by the recovery of melanin hair pigment in the copper-deficient black hooded rat after feeding copper supplements. The role of copper in melanin production has been outlined by Keil \& Nelson (I93I) and Lerner, Fitzpatrick, Calkins \& Summerson (1950). Although growth failure is a common feature of copper-deficiency disorders in farm livestock the evidence from experimental work is contradictory as to whether or not the growth rate of supplemented deficient animals can be used as a third index of copper utilization. It was thought that further information on the relationship of growth to dietary copper intake might be of value.

\section{EXPERIMENTAL AND RESULTS}

\section{General}

Copper determinations. Copper analyses of rat livers, herbage and herbage extracts were carried out by a modification of the diethyldithiocarbamate method of Eden \& Green (1940). The yellow copper diethyldithiocarbamate complex was extracted into 2 or $5 \mathrm{ml}$. of amyl alcohol, depending on the quantity of copper present, and the absorption at $432 \mathrm{~m} \mu$ was determined with a Beckman spectrophotometer.

Haemoglobin determinations. Blood samples were obtained by puncture of the tail artery and vein. Haemoglobin was determined by a modification of the method of Nicholas (I95I), the absorption of oxyhaemoglobin in $0.007 \mathrm{~N}-\mathrm{NH}_{3}$ solution being measured at $540 \mathrm{~m} \mu$ with the Beckman spectrophotometer.

Hair-pigment assay. Black hooded rats were partly depleted of their copper reserves, and a series of pelts showing different stages in the development of grey hair was prepared. Experimental animals were given a 'pigmentation index' by comparison with these pelts, an index of $I$ indicating very severe depigmentation and an index of Io indicating no depigmentation.

Preparation of copper-deficient rats. (I) Preweaning treatment: Pregnant females of the Rowett Institute strain of black hooded Lister rats were housed in heavily galvanized suspended cages and provided with cotton wool as bedding just before the birth of the litter. The litter was reduced to at most six immediately after birth, only female animals being retained. Animals were reared before weaning by a modification 
of the technique of Elvehjem \& Kemmerer (193I) in which a basal diet of fresh milk supplemented as shown in Table $\mathrm{I}$ is fed ad lib. to weanlings and dam in acidwashed glass feeding jars. Dams were removed from the rearing cages for three $\mathrm{I} h$ periods daily so that they could be fed on a stock diet.

\section{Table I. Vitamin supplementation of copper-deficient basal diets of fresh whole milk}

\begin{tabular}{|c|c|c|}
\hline & $\begin{array}{l}\text { Preweaning diet } \\
\text { (mg/l. fresh whole } \\
\text { milk) }\end{array}$ & $\begin{array}{c}\text { Postweaning diet } \\
\text { ( } \mu \mathrm{g} / \mathrm{rat} / \mathrm{day}, \text { given by mouth) }\end{array}$ \\
\hline Thiamine & $0 \cdot 3$ & $12 \cdot 5$ \\
\hline Riboflavin & 0.4 & 21 \\
\hline Pyridoxin & 0.2 & 10 \\
\hline Ca pantothenate & $2 \cdot 0$ & In aqueous solution \\
\hline Folic acid & 0.2 & 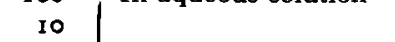 \\
\hline Nicotinic acid & 0.2 & 10 \\
\hline$p$-Aminobenzoic acid & 0.2 & ro \\
\hline $\begin{array}{l}\text { Vitamin A (alcohol) } \\
\text { a-Tocopheryl acetate }\end{array}$ & $\begin{array}{l}7 \cdot 5 \\
5 \cdot 0\end{array}$ & $\left.\begin{array}{r}37 \\
2400\end{array}\right\}$ In arachis oil \\
\hline
\end{tabular}

(2) Postweaning copper-depletion diet: Animals were weaned at the 23 rd day. Fresh whole milk was supplemented with dried skim milk at the rate of $5 \circ \mathrm{g} / \mathrm{l}$. and fed $a d$ lib. Vitamin supplements were given per os, as shown in Table I (column 3). A ferricchloride supplement was purified as follows: Ferrous ammonium sulphate (A.R.) was recrystallized three times, dissolved in glass-distilled water and treated with $\mathrm{H}_{2} \mathrm{~S}$ to remove traces of copper by precipitation as CuS. The supernatant liquid was boiled with a slight excess of redistilled $\mathrm{HNO}_{3}$ (conc. A.R.) to oxidize the iron to the ferric state, and ferric hydroxide was precipitated with an excess of conc. $\mathrm{NH}_{3}$ solution (A.R. sp. gr. 0.880). The precipitate was washed first with $0.5 \mathrm{~N}-\mathrm{HNO}_{3}$ and then with glass-distilled water. The washed precipitate was dried at $40^{\circ}$ to constant weight. This product was weighed for the preparation of stock supplements as $\mathrm{Fe}(\mathrm{OH})_{3}$ and dissolved in the minimum quantity of boiling conc. $\mathrm{HCl}$ (redistilled A.R.) before administration per os by pipette at the rate of $0.5 \mathrm{mg} \mathrm{Fe} \mathrm{e}^{3+} / \mathrm{rat} /$ day. After 45 days on this régime copper reserves became severely depleted, and there was marked anaemia, extensive greying of hair and loss of weight. In earlier experiments it was found inadvisable to let haemoglobin levels fall below $3.5 \mathrm{~g} / \mathrm{roo} \mathrm{ml}$. blood, to avoid losses due to the failure of animals to respond to the feeding of copper supplements at a later stage.

\section{Experiment I}

The main object of this experiment was to determine whether the copper compounds of herbage are as readily utilized by the copper-deficient rat as copper in the form of an inorganic salt. A secondary object was to determine whether the results of chemical studies (Mills, 1954) on the copper of normal herbage and of herbage from areas where the conditioned copper-deficiency disorder 'swayback' of sheep is common are reflected by differences in the physiological availability of copper from these two sources to the rat. 


\section{Methods}

Preparation of herbage samples. Herbage samples were gathered by hand plucking from a farm where 'swayback' has not occurred (Duthie Experimental Stock Farm, Bucksburn, Aberdeenshire) and from an area where 'swayback' is common if copper supplements are withheld from pregnant ewes (Upper Shatton Farm, Bradwell, Derbyshire).* Samples were packed in solid carbon dioxide for transport to the laboratory and were stored at $-20^{\circ}$ until required for freeze drying. Dried samples were milled in a carefully cleaned Christy \& Norris laboratory hammer mill (screen 64) before feeding. Samples selected for this experiment had approximately the same content of copper-the 'normal' sample used contained $13.6 \mu \mathrm{g} \mathrm{Cu} / \mathrm{g}$ dry matter and the 'swayback' sample $\mathrm{I} 3 \cdot 2 \mu \mathrm{g} \mathrm{Cu} / \mathrm{g}$ dry matter.

Experimental diets. The copper-deficient basal diet was fed ad lib. to all animals. Animals were randomized according to litter into five treatment groups, five animals receiving each test supplement. Test supplements were fed as indicated in Table 2 . These were given $3 \mathrm{~h}$ after all food had been removed from the rat cages and food was not replaced until $\mathrm{I} h$ later, to reduce the interaction of these supplements with the basal diet.

\section{Results}

Group means for haemoglobin values, weights, pigmentation indices and livercopper contents, for the beginning and end of the experimental period, together with standard errors of differences, are given in Table 2. Intermediate values obtained during the experimental period are presented graphically in Fig. I.

Haemoglobin regeneration. There were no significant differences in the Hb levels between groups at the beginning of the experimental period. By the end of the experiment dietary effects were highly significant $(P<0.00 \mathrm{I})$. 'The final $\mathrm{Hb}$ level for group I (copper-deficient control) was significantly lower than for all other groups $(P<0.001)$. (The results for two animals of this group that died before the end of the experiment were excluded from the statistical analysis.)

The final $\mathrm{Hb}$ levels attained by the animals of groups 2 and 3 (receiving ro and I2.5 $\mu \mathrm{g}$ ionic $\mathrm{Cu} /$ day) were similar and their difference was not significant. The mean $\mathrm{Hb}$ level of the animals receiving ionic copper (groups 2 and 3 ) was $9.32 \mathrm{~g} / 100 \mathrm{ml}$. blood; the corresponding mean for the animals receiving herbage providing $12.5 \mu \mathrm{g}$ $\mathrm{Cu} /$ day (groups 4 and 5 ) was $15.01 \mathrm{~g} / 100 \mathrm{ml}$. blood. The standard error of this difference was \pm 0.33 with $P<0.00$ r.

The difference in haematopoietic response to copper in 'normal' and in 'swayback' herbage was not significant.

Weight response. Initial differences in the mean live weight of experimental groups were not significant. The overall treatment effects at the end of the experiment were significant $(P<0.0 \mathrm{I})$. The general pattern of these differences was similar to those obtained with the haemoglobin results. The difference in final weight between the animals of groups I and 2 was significant $(P<0.05)$, as was that between groups $I$ and $3(P<0.01)$. The difference between group 2 and group 3 was not significant. The

\footnotetext{
* These samples are hereafter referred to as 'normal' or 'swayback' herbages respectively.
} 


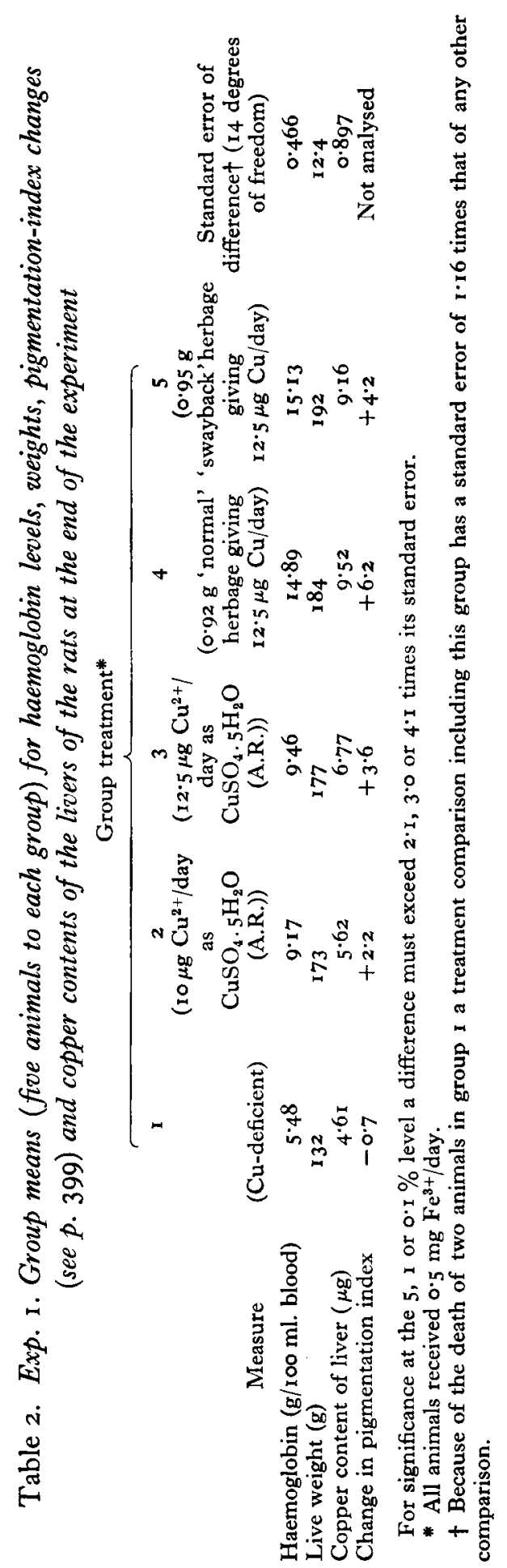


mean final weight of the animals receiving ionic copper was $175 \mathrm{~g}$ and the corresponding mean for animals receiving herbage copper was $188 \mathrm{~g}$. This difference was not significant.

The difference in final weight of the 'normal' and 'swayback' groups was not significant.

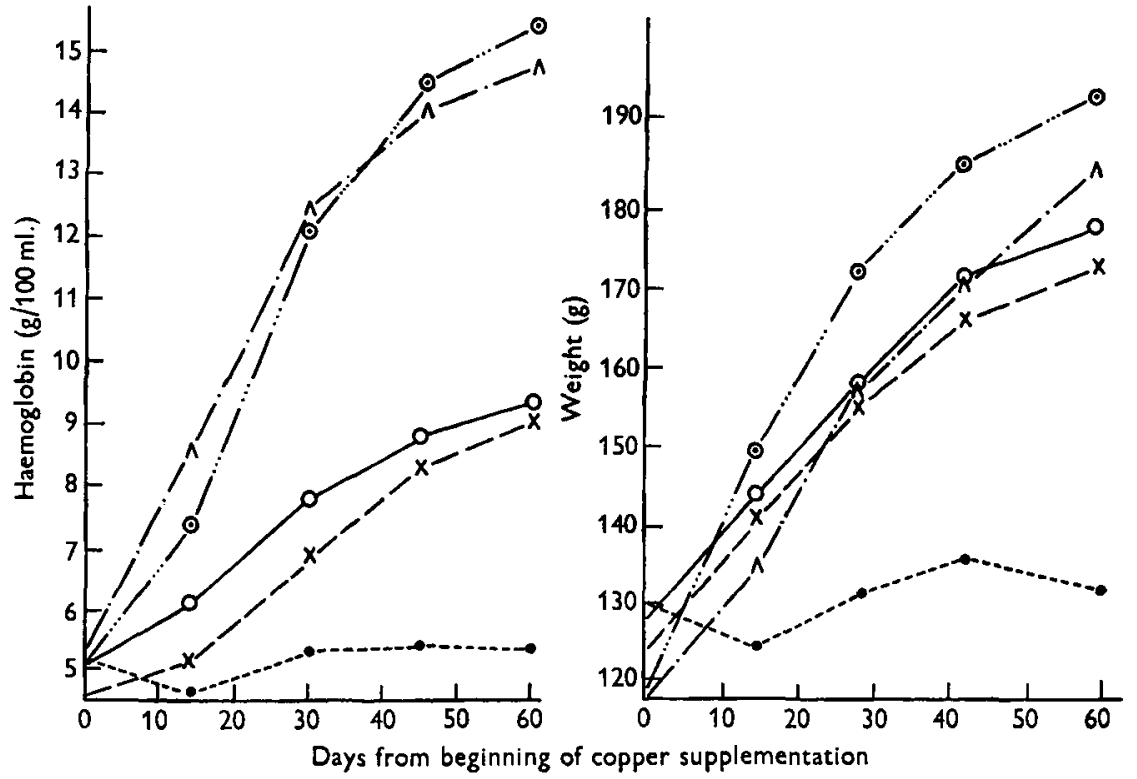

Fig. I. Exp. I. Haemoglobin and growth responses of copper-deficient rats after copper supplementation (five rats to each treatment group, see second footnote to Table 2)..--- , Cu-deficient control; $x--x$, I0 $\mu \mathrm{g} \mathrm{Cu}^{2+}$ as $\mathrm{CuSO}_{4} \cdot 5 \mathrm{H}_{2} \mathrm{O} ; 0-\mathrm{O}, \mathrm{I2} \cdot 5 \mu \mathrm{g} \mathrm{Cu}^{2+}$ as $\mathrm{CuSO}_{4} \cdot 5 \mathrm{H}_{2} \mathrm{O}$; $\wedge$ - - - $12.5 \mu \mathrm{g} \mathrm{Cu}$ as 'normal' herbage; $-\ldots-\ldots-\odot, 12.5 \mu \mathrm{g} \mathrm{Cu}$ as 'swayback' herbage.

Copper content of the liver. Differences appeared in the copper contents of the livers of animals of groups I, 2 and 3 , but they were not statistically significant, although the difference between group $I$ and group 3 just failed to reach significance with $0.05<P<0.1$. The overall mean liver-copper level for groups 2 and 3 receiving inorganic copper was $6.77 \mu \mathrm{g}$ and for groups 4 and 5 receiving herbage, $9.34 \mu \mathrm{g}$. The standard error was \pm 0.78 with $P<0.001$. The small difference in the liver-copper contents resulting from the feeding of 'normal' and 'swayback' herbage was not significant.

Hair pigmentation. The results of hair-pigment assessment were not statistically analysed. Nevertheless, the results presented in Table 2 show good agreement with those outlined above. There was no evidence of pigment regeneration in the copperdeficient control group. There was a suggestion that the animals of group $3(12.5 \mu \mathrm{g}$ $\mathrm{Cu}^{2+} /$ day) regenerated pigment more rapidly than those of group 2 (IO $\mu \mathrm{g} \mathrm{Cu}^{2+} /$ day). The recovery of hair pigment was most marked in the animals receiving herbage supplements.

\section{Experiment 2}

The observation in Exp. I that the physiological response of the copper-deficient rat is greater when herbage supplements are fed than when these are replaced by corresponding quantities of inorganic copper made it desirable to determine whether 
the agent responsible was soluble in water or in fat solvents. Although most available evidence supports the view that copper acts as a specific inorganic supplement to iron for haematopoiesis, many workers (e.g. 'Titus \& Cave, I928; Titus, Cave \& Hughes, 1928; Titus \& Hughes, I929; Mitchell \& Miller, I929; Drabkin \& Waggoner, I930; Myers \& Beard, I93I) have questioned the specificity of copper. It has been suggested by Elvehjem (1935) that the results of these workers are attributable to incomplete removal of contaminating copper from the inorganic supplements tested; nevertheless, it was considered advisable to feed an ash of herbage treated with hydrochloric acid to one group of animals in Exp. 2 to examine the possibility that some element present in herbage might exert a potentiating effect on iron and copper for haematopoiesis.

\section{Methods}

Preparation of herbage fractions. A sample of freeze-dried herbage from the Rowett Institute farm with a copper content of $8.55 \mu \mathrm{g} / \mathrm{g}$ dry matter was used for this work. This herbage was fed to group I animals ( $0.29 \mathrm{~g}$ daily) to give an intake of $2.5 \mu \mathrm{g}$ $\mathrm{Cu} /$ day. A water-soluble extract was prepared by stirring $29^{\circ} \mathbf{2} \mathrm{g}$ of milled grass for $18 \mathrm{~h}$ with $\mathrm{I} \cdot 5 \mathrm{l}$. glass-distilled water at $37^{\circ}$. After centrifuging at $8000 \mathrm{~g}$ for $\mathrm{I} \mathrm{h}$ the supernatant liquid was withdrawn in $15 \mathrm{ml}$. portions for freeze drying. The hygroscopic product was stored in stoppered bottles at $-20^{\circ}$. The concentrate of one I $5 \mathrm{ml}$. portion was fed to each rat daily.

A fraction soluble in light petroleum (b.p. 40-60 ) was prepared by extracting $29.2 \mathrm{~g}$ herbage in a Soxhlet for $24 \mathrm{~h}$. The extracts were pooled and concentrated under reduced pressure in a nitrogen stream. As the concentration proceeded $20 \mathrm{ml}$. arachis oil were added. The materials soluble in light petroleum thus remained dissolved in oil at the end of the distillation. This concentrate was stored in vacuo at $-20^{\circ}$. Of this product $0.2 \mathrm{ml}$. was fed to each rat daily. The inorganic ash of herbage was prepared for feeding by incineration of $0.29 \mathrm{~g}$ samples to a light-grey ash. Two drops conc. $\mathrm{HCl}$ were added to the ash and the product was evaporated to dryness at $100^{\circ}$. The ash was moistened with $0.1 \mathrm{ml} .2 \%$ sucrose solution before feeding.

Treatment of animals. Animals were depleted of their copper reserves as in Exp. I and randomized according to litter into six treatment groups, six animals receiving each test supplement. Test supplements were fed as indicated in Table 3. To minimize interactions with the basal diet all food was removed $3 \mathrm{~h}$ before feeding supplements and replaced $\mathrm{I} h$ after.

\section{Results}

Group means and the standard error of their differences at the end of the experiment are presented in Table 3. Results for haemoglobin and live weight during the experimental period are presented graphically in Fig. 2.

Diet I (freeze-dried grass to give $2.5 \mu \mathrm{g} \mathrm{Cu} /$ day) was superior in all measures to diet $5\left(2.5 \mu \mathrm{g} \mathrm{Cu}{ }^{2+} /\right.$ day), with $P<0.00$ I. Diet I was also superior to diet $6(25 \mu \mathrm{g}$ $\mathrm{Cu}^{2+} /$ day $)$ in its haematopoietic action $(P<0.0 \mathrm{I})$ and resulted in a greater storage of copper in the liver $(P<0.05)$. There was no difference in the rates of hair-pigment regeneration in these two groups. 
Vol. 9

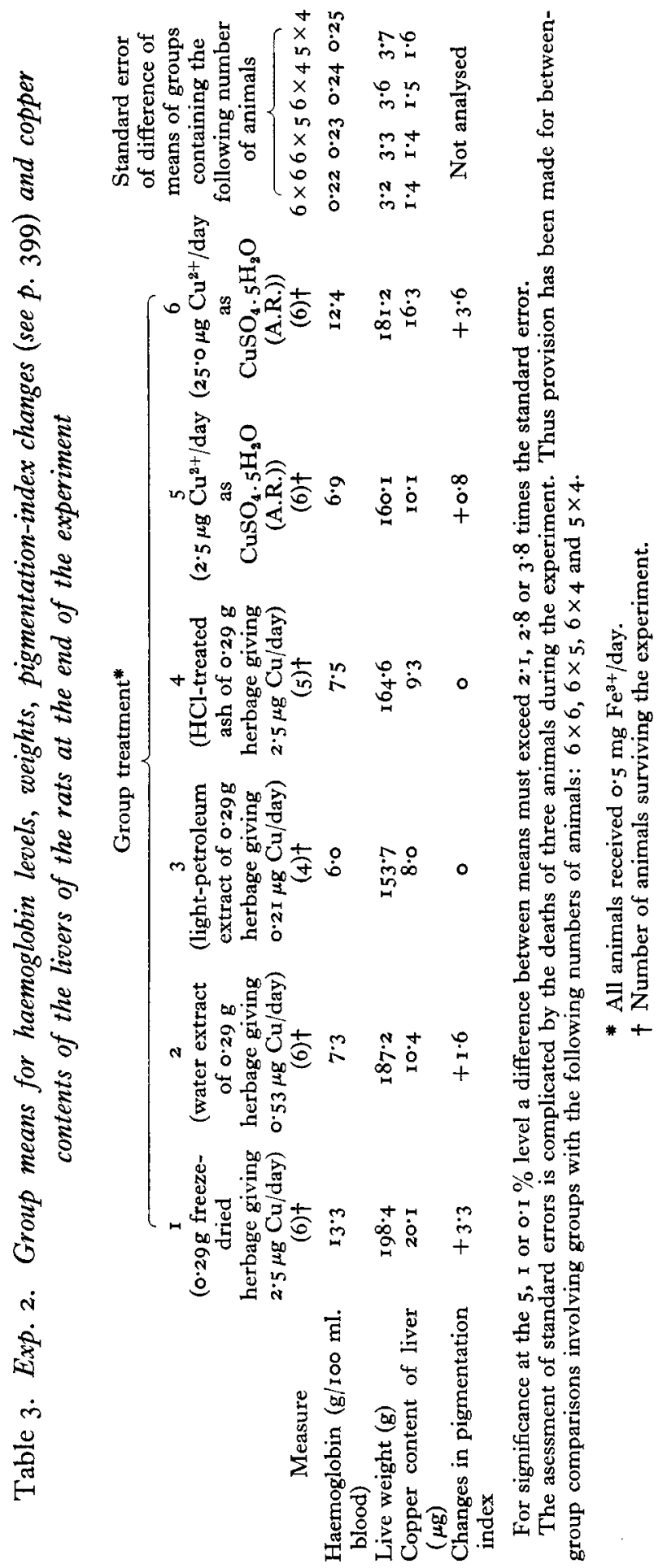


Diet 2 (aqueous extract of herbage) initially gave a more rapid haemoglobin recovery than diet 5 , but by the end of the experiment the difference was not significant nor was the difference between the copper content of the livers, in spite of the lower copper content of diet 2. The final weights of the animals on diet 2 were significantly greater $(P<0.01)$ than on diet 5. On the other hand, the daily feeding of $25 \mu \mathrm{g}$ inorganic copper (diet 6) gave a better overall response than diet 2.

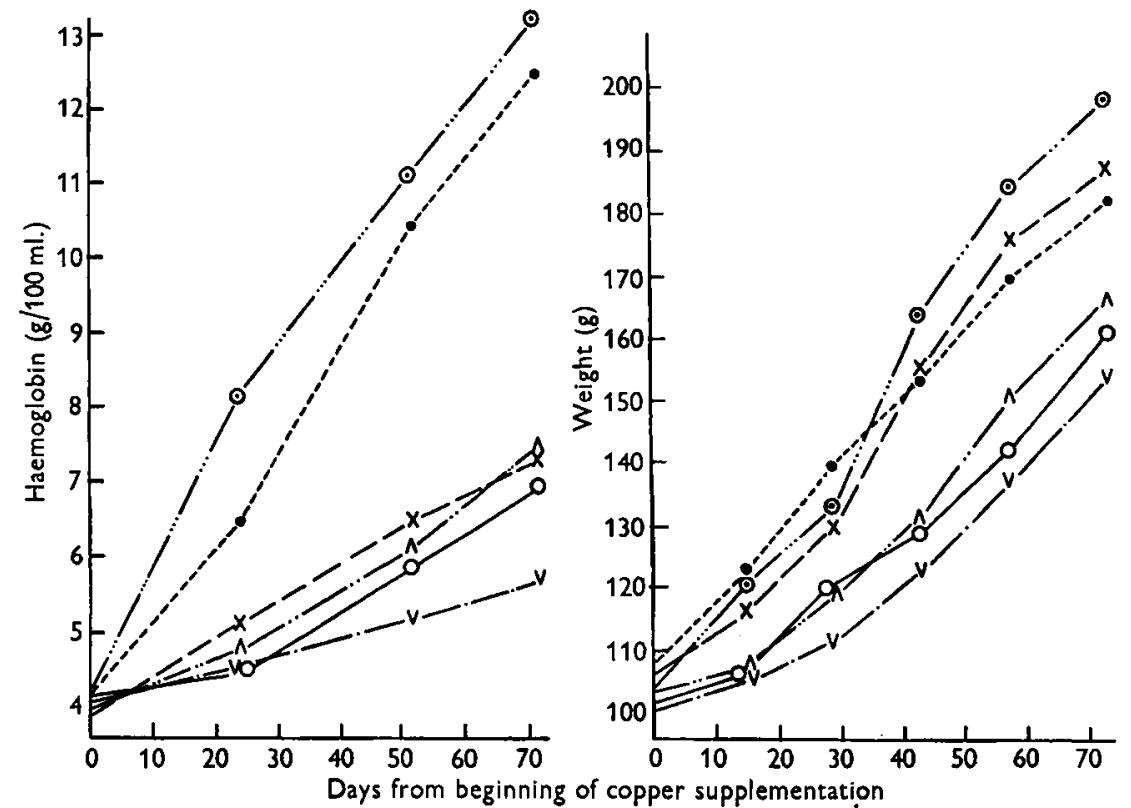

Fig. 2. Exp. 2. Haemoglobin and growth responses of copper-deficient rats after copper supplementation (six rats to each treatment group, see second note to Table 3 ). $\odot-\cdots-\odot, 2^{\prime} 5 \mu \mathrm{g} \mathrm{Cu}$ as $0.29 \mathrm{~g}$ herbage; $\times---\times$, water extract of $0.29 \mathrm{~g}$ herbage; $v-\cdots$, light petroleum extract of $0.29 \mathrm{~g}$ herbage; $\wedge-\cdots-\Lambda$, ash of $0.29 \mathrm{~g}$ herbage; $\mathrm{O}-\mathrm{O},{ }_{2} \cdot 5 \mu \mathrm{g} \mathrm{Cu}{ }^{2+}$ as $\mathrm{CuSO}_{4} \cdot{ }_{5} \mathrm{H}_{2} \mathrm{O}$; - - - - $25 \mu \mathrm{g} \mathrm{Cu}^{2+}$ as $\mathrm{CuSO}_{4} \cdot 5 \mathrm{H}_{2} \mathrm{O}$.

The rate of recovery on diet 3 (light-petroleum extract) was markedly inferior to that obtained with diet 5 . The copper content of the liver on this diet was lower than on diet 5 , but the difference just failed to reach significance $(0.05<P<0.1)$. There was no evidence of hair-pigment regeneration on diet 3 .

The ash of herbage treated with hydrochloric acid (diet 4 giving $2.5 \mu \mathrm{g} \mathrm{Cu}^{2+} /$ day) gave results very similar to those on diet 5 . None of the differences between these two groups of animals were statistically significant, nor was there a difference in the rate of hair-pigment regeneration.

\section{DISCUSSION}

In both experiments some animals on the diets giving the least effective recovery from copper deficiency died. The results for these animals were not included in the statistical analysis, and this omission would raise the corresponding group means. Since the bias is in the 'safe' direction it does not affect the conclusions to be drawn. 
The outstanding feature of Exp. I was the superiority of the response obtained when copper was fed in the form of a grass supplement, compared with that obtained from an equivalent quantity of copper as cupric sulphate. This result was obtained for haemoglobin regeneration, hair-pigment formation, growth and liver-copper storage. These findings together with the precautions taken to ensure that the basal ration was otherwise adequate, suggest that these responses were due to the presence of a readily available source of copper in herbage.

This result was confirmed by Exp. 2, and it was further shown that these differences disappeared after a tenfold increase in the daily intake of cupric sulphate. It is clear that the rapid response to grass feeding was not due to inorganic elements other than copper in the herbage, since the feeding of an ash treated with hydrochloric acid gave an overall response that was in no way superior to that obtained with the corresponding quantity of cupric sulphate.

The response obtained with a light-petroleum soluble fraction of herbage was poor; although haemoglobin regeneration took place to a limited extent in some animals, others failed to respond and ultimately died with severely depleted liver-copper stores. The overall performance of animals in this group was not sufficiently encouraging to warrant further study of the components of herbage soluble in light petroleum.

On the other hand, much more striking effects were obtained from a concentrated aqueous extract of herbage containing small quantities of copper. The daily allocation of $0.53 \mu \mathrm{g}$ copper in this concentrate raised the liver-copper status slightly more than the feeding of $2.5 \mu \mathrm{g}$ copper as cupric sulphate. Further evidence of the ready utilization of copper in the aqueous concentrate was provided by the physiological response which was, if anything, better than that obtained with $2.5 \mu \mathrm{g} /$ day of the cupric ion.

These results suggest that the rapid recovery from copper deficiency of rats receiving herbage or an aqueous extract of herbage is due to factors in these materials that promote the absorption and utilization of dietary copper. It is of interest that the results of Hart, Elvehjem, Waddell \& Herrin (1927) indicate that fresh lettuce, maize grain and spleen marrow have a higher haematopoietic potency than the inorganic ashes of these materials when fed to the copper-deficient rabbit. Later, Schultze et al. (1936) found that wheat germ had a higher potency than an equivalent quantity of the cupric ion fed to the copper-deficient rat. Since these results were obtained with a nutritionally inadequate fresh-milk basal diet, and since the haematopoietic response was used as the sole index of copper uptake, the similarity between these results and those of the present investigation must not be unduly emphasized. Nevertheless, these findings demonstrate that certain biological materials contain copper in a form more readily utilized than inorganic copper salts.

In Exp. I it was not possible to demonstrate differences in the utilization of copper from 'normal' and 'swayback' grass. This result has been confirmed in subsequent experiments with herbage samples gathered at different seasons. Earlier studies (Mills, I954) indicated that rather less copper was water-soluble in 'swayback' than in 'normal' herbage. This difference does not apparently limit the physiological utilization of copper from 'swayback' herbage by the rat, whereas when this material is fed as the sole source of copper to the sheep, copper reserves become steadily 
depleted. Two possible explanations are suggested to account for this difference. It is possible that in the sheep fed 'swayback' herbage the metabolic products of rumen micro-organisms may limit the utilization of dietary copper either by combining with this element to form non-available compounds or by affecting the metabolic activity of the mucosa of the digestive tract. Alternatively, this difference may merely be due to the feeding of a supplemented basal diet with herbage samples in availability trials with the rat. Thus, if a dietary factor required for the utilization of copper is present in 'normal' but lacking in 'swayback' herbage, and if this factor is provided by the basal diet, it would be impossible to demonstrate differences in the availability of copper in 'normal' and 'swayback' herbage by means of this technique.

\section{SUMMARY}

I. Animals of the Rowett Institute strain of black hooded Lister rats were depleted of copper on a basal diet of supplemented milk. These animals were used for copperavailability trials in which the utilization of dietary copper was assessed by haematopoietic response, melanin-pigment regeneration, growth response and copper content of the liver.

2. A superior physiological response and greater storage of copper in the liver resulted from the feeding of herbage supplements than from the administration of equivalent amounts of cupric sulphate.

3. This response was associated with the copper of the water-soluble component of herbage. A light petroleum-soluble extract of herbage was virtually inactive and the hydrochloric-acid treated ash of herbage showed no greater physiological activity than the corresponding quantity of copper administered as cupric sulphate.

4. It is suggested that the water-soluble component of herbage contains copper in a form more readily available than the free cupric ion.

5. No difference could be demonstrated in the availability of copper from 'normal' and 'swayback' herbage in these experiments. The possible significance of this finding is discussed.

I wish to thank Dr J. Duckworth for his advice and encouragement while this work was in progress. Thanks are due to Messrs G. Park and A. W. Boyne for the statistical analysis of results reported in this paper. I am indebted to Miss Grace Murray and to Messrs J. W. C. Davis, N. Robertson and A. Forbes for valuable technical assistance.

\section{REFERENCES}

Allcroft, R. \& Parker, W. H. (1949). Brit. F. Nutr. 3, 205.

Drabkin, D. L. \& Waggoner, C. S. (1930). F. biol. Chem. 89, 51.

Eden, A. \& Green, H. H. (1940). Biochem. Y. 34, 202.

Elvehjem, C. A. (1935). Physiol. Rev. 15, 471 .

Elvehjem, C. A. \& Kemmerer, A. R. (I93I). F. biol. Chem. 93, 189.

Hart, E. B., Elvehjem, C. A., Waddell, J. \& Herrin, R. C. (1927). F. biol. Chem. 72, 299.

Keil, H. L. \& Nelson, V. E. (1931). F. biol. Chem. 93, 49.

Lerner, A. B., Fitzpatrick, T. B., Calkins, E. \& Summerson, W. H. (1950). 7. biol. Chem. 187, 793.

Marston, H. R. (1950). In Copper Metabolism-A Symposium on Animal, Plant and Soil Relationships. [W. D. McElroy and B. Glass, editors.] Baltimore: Johns Hopkins Press. 
Marston, H. R. (195 I). Plant and Animal Nutrition in Relation to Soil and Climatic Factors. London: H.M. Stationary Office.

Marston, H. R. (1952). Physiol. Rev. 32, 66.

Mills, C. F. (1954). Biochem. F. 57, 603.

Mills, C. F. (1955). A study of the metabolism of copper complexes present in grassland herbage. Thesis, University of London.

Mitchell, H. S. \& Miller, L. (r929). F. biol. Chem. 85, 355.

Myers, V. C. \& Beard, H. H. (I93I). F. biol. Chem. $94,89$.

Nicholas, J. W. (1951). Biochem. F. 50, 1.

Schultze, M. O. (1940). Physiol. Rev. 20, 37.

Schultze, M. O., Elvehjem, C. A. \& Hart, E. B. (1934). F. biol. Chem. I06, 735.

Schultze, M. O., Elvehjem, C. A. \& Hart, E. B. (1936). F. biol. Chem. 115, 453.

Taylor, A. E., Long, J. H. \& Chittenden, R. H. (1913). Rep. U.S. Dep. Agric. no. 97.

Titus, R. W. \& Cave, H. W. (1928). Science, 68, 410.

Titus, R. W., Cave, H. W. \& Hughes, J. S. (1928). F. biol. Chem. 80, 565.

Titus, R. W. \& Hughes, J. S. (1929). F. biol. Chem. 83, 463 .

Tschirch, A. (1893). Das Kupfer. Stuttgart: Ferd. Enke. 